Original Research

\title{
Effect of Physicochemical Wastewater Parameters and Abiotic Factor on Activated Sludge Sedimentation Capacity
}

\author{
Bartosz Szeląg ${ }^{1 *}$, Jan Studziński ${ }^{2}$ \\ 'Faculty of Environmental, Geomatic and Energy Engineering, Kielce University of Technology, Kielce, Poland \\ ${ }^{2}$ Centre for Computer Science Applications in Environmental Engineering, Systems Research Institute, \\ Polish Academy of Sciences, Warszawa, Poland
}

Received: 6 March 2018

Accepted: 29 April 2018

\begin{abstract}
This article analyzes the effect that the physicochemical parameters of the wastewater flowing into a treatment plant have on the activated sludge settleability. The statistical analysis shows that as far as the technological parameters are concerned, the activated sludge sedimentation capacity is mostly affected by the biomass concentration in the chamber, whereas as for the abiotic factors, settleability is significantly determined by the season of the year and thus the temperature. With regard to the wastewater quality-related parameters, biological oxygen demand has the greatest effect on settleability. The conducted analyzes involved the development of statistical models to predict the activated sludge sedimentation capacity on the basis of multiple linear regression and genetic programming.
\end{abstract}

Keywords: activated sludge, sedimentation capacity, genetic programming, wastewater treatment plant

\section{Introduction}

Modern biological wastewater treatment plants that remove carbon, nitrogen and phosphorus often use activated sludge technology. This method is based on a complex biological system, whose fundamental structural unit is a sludge flock composed of microorganisms, extracellular polymeric substances (EPS), inorganic particles (e.g., sand or clay) and water $[1,2]$. The analysis of the shape, structure and size of flocks shows to what extent morphological features affect sludge settleability. Dense flocks have a higher specific weight than loose flocks and hence their settleability is better. Large and tough flocks

*e-mail: bszelag@tu.kielce.pl will settle more easily than weak and fine ones, which tend to remain suspended in the liquid, leading to an increase in the suspended solids concentration in the effluent. Thus, obtaining flocks with desirable properties will facilitate the correct course of the flocculation process, which is crucial for the effective reduction of pollutants in wastewater. Settleability is an important parameter defining the activated sludge sedimentation capability. It is determined relatively quickly and easily, consisting in measuring the volume of sludge after a 30-minute sedimentation in a one-liter Imhoff funnel. Activated sludge settleability is an important parameter determining the value of the sludge index and the suspended solids content in the treated effluent.

A literature review [3-7] reveals that the activated sludge sedimentation capabilities are determined by temperature, biochemical oxygen demand (BOD) 
load, sludge age, the concentration of oxygen in the nitrification chamber, recirculation level, sludge concentration in the bioreactor, and the use of chemical coagulants as well as the presence of filamentous bacteria. Therefore, the systematic monitoring of settleability provides important data on the activated sludge condition. Such information may indicate a malfunction in the operation of the wastewater treatment plant and thus impose taking corrective measures. However, the effect of abiotic factors, such as meteorological conditions, on the activated sludge settleability has not hitherto been analyzed. Sludge sedimentation capabilities expressed with the settleability parameter are omitted in scientific research studies since it is assumed that in practice one cannot separate the settleability parameter from the dry weight of the activated sludge (as the dry weight concentration is low, the settleability is lower as well). Nevertheless, the value of settleability conveys information on the effectiveness of the activated sludge suspended solids sedimentation, the parameter that can be easily explored in each wastewater treatment plant.

Mathematical models have been used on numerous occasions to predict sludge sedimentation capabilities [8-15], whereby due to the complex nature of the processes occurring in activated sludge they were black-box models, in which the structure of the model is generated at the stage of learning without having to know the physical laws that describe the analyzed phenomenon. The disadvantage of these models is that one cannot clearly determine the impact of particular explanatory variables on the dependent variable. They also require the implementation of complex numerical algorithms, which is a significant limitation at the stage of the wastewater treatment plant operation.

Therefore it is advisable to analyze the effect of the meteorological conditions, the physicochemical parameters of the wastewater reaching the treatment plant and the bioreactor parameters on the sedimentation capabilities of the activated sludge. The analyses under consideration were based on the measurement results of the parameters listed above, obtained during the years 2012-2015 in a laboratory of the wastewater treatment plant Sitkówka - Nowiny near Kielce (Poland). The collected measurement results provided the basis for determining the correlation matrix and for the development of simple models to calculate activated sludge settleability with the application of the relations established by genetic programming and multiple linear regression.

\section{Material and Research Object}

The study focused on the municipal wastewater treatment plant located in the municipality of Sitkówka-Nowiny, which collects sanitary wastewater from the separate wastewater system of the city of Kielce, the municipality of Sitkówka-Nowiny and a certain part of the municipality of Masłów. The nominal capacity of the plant is $72.000 \mathrm{~m}^{3} / \mathrm{d}$ with a load of 275.000 person.

Wastewater reaching the plant undergoes preliminary treatment, accomplished by using equipment such as bar screens and aerated sand traps with grease separators. Then the wastewater is pumped into four primary settling tanks, from which the primary sludge is directed to the secondary sludge pump station. After mechanical treatment the wastewater flows to the biological treatment section. In the initial denitrification chambers (into which the activated sludge is recirculated), the partial removal of nitrogen compounds takes place. Then the wastewater is directed to the dephosphatation chambers, where phosphorus compounds are removed by chemical and biological methods. The bioreactor with denitrification and nitrification chambers, in which the contaminants are ultimately removed from wastewater, is the most crucial component of the treatment plant. The wastewater with the activated sludge flows into four secondary settling tanks, from where, after clarification, it is directed to the receiver: the Bobrza River.

Within the framework of the constant monitoring conducted by Kielce Waterworks (Wodociągi Kieleckie Sp. $\mathrm{z}$ o.o.) the following parameters have been measured in the wastewater treatment plant at weekly intervals since 2012: the value of chemical and biochemical oxygen demand, ammonia, nitrate and nitrate nitrogen, Kjeldahl nitrogen, total nitrogen, total suspended solids, permanganate index, total phosphorus, chlorides, sulfates, $\mathrm{pH}$ and temperature in the treated and raw wastewater and in the activated sludge. In different technological facilities involved in the wastewater treatment process at the treatment plant, the following parameters are measured on a daily basis: the amount of primary and excessive sludge, oxygen concentration in activated sludge chambers (ASC), the concentration of sludge in the reactor, the recirculation degree and the concentration of suspended solids in the recirculated sludge, methanol and coagulant PIX dosage. The observed everyday abiotic factors related to meteorological conditions included air temperature, pressure, wind velocity, relative humidity and the season of the year.

\section{Methods}

The correlation matrix was developed in order to determine the effect of meteorological conditions, bioreactor performance parameters and the quantity and quality of the inflowing wastewater on the activated sludge settleability (SE). When the analyzed variables were similar in nature to the normal ones, Pearson's correlation coefficient was determined, in other cases Spearman's correlation coefficient was applied. Guilford's classification (Table 1) was used to assess the correlations between the analyzed variables. The identification of the normal distribution was based on the 
Table 1. Ranges and values of the analyzed parameters.

\begin{tabular}{|c|c|c|c|c|c|}
\hline Variable & Range & Mean & Variable & Range & Mean \\
\hline $\mathrm{m}_{\text {pr.cl }} ; \mathrm{kg}$ & $54 \div 317$ & 173.5 & $\mathrm{NO}_{2}^{-} ; \mathrm{mg} / \mathrm{dm}^{3}$ & $0.00 \div 1.55$ & 0.16 \\
\hline $\mathrm{Q}_{\text {inf }} ; \mathrm{m}^{3} / \mathrm{d}$ & $32564 \div 86592$ & 40698 & $\mathrm{~N}_{\text {total }} ; \mathrm{mg} / \mathrm{L}$ & $39.91 \div 124.10$ & 77.7 \\
\hline $\mathrm{T}_{\mathrm{inf}} ;{ }^{\circ} \mathrm{C}$ & $10.6 \div 20.9$ & 16.4 & $\mathrm{P}_{\text {total }} ; \mathrm{mg} / \mathrm{L}$ & $4.3 \div 12.6$ & 7.8 \\
\hline $\mathrm{T}_{\text {air }} \cdot{ }^{\circ} \mathrm{C}$ & $-12.0 \div 36.0$ & 12.2 & $\mathrm{Cl}^{-} ; \mathrm{mg} / \mathrm{L}$ & $85 \div 184$ & 144 \\
\hline $\mathrm{p}_{\mathrm{air}}, \mathrm{Pa}$ & $966.0 \div 1015$ & 984.0 & $\mathrm{SO}_{4}^{2} ; \mathrm{mg} / \mathrm{L}$ & $43 \div 117$ & 81.5 \\
\hline $\mathrm{pH}$ & $7.0 \div 8.1$ & 7.6 & $\mathrm{BOD} ; \mathrm{mgO}_{2} / \mathrm{L}$ & $127 \div 557$ & 309 \\
\hline W.V.; m/s & $0 \div 25$ & 12.2 & $\mathrm{COD} ; \mathrm{mgO}_{2} / \mathrm{L}$ & $384 \div 1250$ & 791 \\
\hline $\mathrm{N}_{\text {Kjeh }}, \mathrm{mg} / \mathrm{dm}^{3}$ & $36.8 \div 124.0$ & 76.5 & TSS; mg/L & $136 \div 572$ & 325 \\
\hline R.H.; \% & $36 \div 99$ & 73.9 & $\mathrm{~s}_{\text {sludge }} ; \mathrm{kg} / \mathrm{m}^{3}$ & $1.97 \div 6.59$ & 4.26 \\
\hline $\mathrm{T}_{\text {sludge }} ;{ }^{\circ} \mathrm{C}$ & $10.0 \div 23.0$ & 15.9 & $\%$ rec & $44.59 \div 167.55$ & 90.70 \\
\hline $\mathrm{PI} ; \mathrm{mg} / \mathrm{dm}^{3}$ & $62 \div 160$ & 108 & $\mathrm{~s}_{\text {sl.rec }} ; \mathrm{mg} / \mathrm{L}$ & $4800 \div 9600$ & 8300 \\
\hline $\mathrm{NH}_{4}^{+} ; \mathrm{mg} / \mathrm{dm}^{3}$ & $24.4 \div 65.9$ & 49.4 & $\mathrm{~m}_{\mathrm{met}} ; \mathrm{m}^{3}$ & $0.00 \div 4.56$ & 1.28 \\
\hline $\mathrm{NO}_{3}^{-} ; \mathrm{mg} / \mathrm{dm}^{3}$ & $0.05 \div 1.10$ & 0.17 & $\mathrm{~m}_{\mathrm{PIX}} ; \mathrm{m}^{3}$ & $0.00 \div 7.93$ & 0.77 \\
\hline $\mathrm{s}_{\mathrm{O} 2,211} ; \mathrm{mg} / \mathrm{dm}^{3}$ & $0.98 \div 3.96$ & 2.38 & $\mathrm{~s}_{\mathrm{O} 2,201,205} ; \mathrm{mg} / \mathrm{dm}^{3}$ & $0.00 \div 0.04$ & 0.02 \\
\hline
\end{tabular}

where: $\mathrm{m}_{\text {pr.cl }}$ - the amount of the primary sludge, $\mathrm{Q}_{\mathrm{inf}}$ - daily flow rate, $\mathrm{T}_{\mathrm{inf}}$ - the temperature of the wastewater the inflow to the treatment plant, $\mathrm{T}_{\text {air }}-$ temperature of the air, W.V. - velocity of the wind, R.H. - relative humidity of the air, $T_{\text {sludge }}-$ temperature of the activated sludge, BOD - biochemical oxygen demand, $\mathrm{COD}$ - chemical oxygen demand, PI - permanganate index $, \mathrm{NH}_{4}^{+}, \mathrm{NO}_{2}^{-}$, $\mathrm{NO}_{3}^{-}, \mathrm{N}_{\mathrm{Kjeh}}, \mathrm{N}_{\text {total }}-$ concentration of: ammonium nitrate, nitrite nitrogen, nitrate nitrogen, Kjeldahl nitrogen, total nitrogen, $\mathrm{TSS}$ - total suspended solid, $\mathrm{P}_{\text {total }}-$ concentration of total phosphorus, $\mathrm{Cl}^{-}$-concentration of chlorides, $\mathrm{SO}_{4}^{2-}$ - concentration of sulfates, $\mathrm{S}_{\text {sludge }}$ - concentration of sludge, $\mathrm{S}_{\mathrm{O} 2(202,204,211)}$ - oxygen concentration in the nitrification chamber, \%rec - recirculation degree, $\mathrm{s}_{\mathrm{sl} . \mathrm{rec} .}$ - concentration of recirculated sludge, $\mathrm{m}_{\mathrm{met}}$ - amount of the dosed metanol, $\mathrm{m}_{\mathrm{PIX}, \mathrm{PAX}}$-amount of the dosed PIX, PAX.

Shapiro-Wilk test at the $\alpha=0.05$ level of significance. The computation results were used to develop models predicting the activated sludge settleability in real time on the basis of meteorological parameters, the quality of influent wastewater and the processes taking place in the treatment plant in the preceding 24 hours. In this discussion the activated sludge settleability was determined using the multiple regression and genetic programming methods.

Linear regression is a well-known technique [13] that enables the calculation of the variable output (y) as the sum of the free term and the products of weights and different input variables:

$$
y=a_{0}+\sum_{n=1}^{N} a_{n} \cdot x_{n}
$$

...where $x_{i}$ is the numerical values of input signals and $\mathrm{a}_{\mathrm{i}}$ is the parameters estimated by the least squares method.

Koza [14] proposed a special type of evolutionary algorithm that he called genetic programming (GP) and which was an extension of genetic algorithm (GA) used to develop programs in (Fig. 1) the form of so-called parse trees solving a formulated problem. This model is based on the collective training of a population of points called individuals. In GP, an individual is represented by a tree that has nodes randomly selected from two sets: tree leaves are defined from the set of terminal arguments (T) and the remaining nodes from the set of functions (F). The terminal set can be composed of independent variables that describe a given phenomenon and invariables, whereas the set of functions contains basic mathematical operators $(+,-, /$, sine, cosine, exp., etc.) that can be used at the stage of model construction. The evolution process starts with a random selection of $\mathrm{n}$ individuals of the population (selection) and then four operations are applied N-times (generations): reproduction, genetic operations, evaluation and succession until the algorithm stopping criterion is met. Stochastic reproduction operator involves selecting $\mathrm{n}$ parent individuals from the current population to generate the offspring. Parent individuals are subject to genetic operators aimed at mixing the information contained therein through crossover and mutation. The offspring individuals created in this way undergo evaluation, i.e. the value of the optimised quality criterion, called the fitness function, is determined. In this study, the correlation coefficient (r) provided the criterion for determining the goodness of fit of the given computation results, obtained using the mathematical formula based on GP with respect to the measurement data. To construct a model for activated sludge settleability predictions, basic mathematical operators of the type,+- , / were used. Moreover, the 
a)

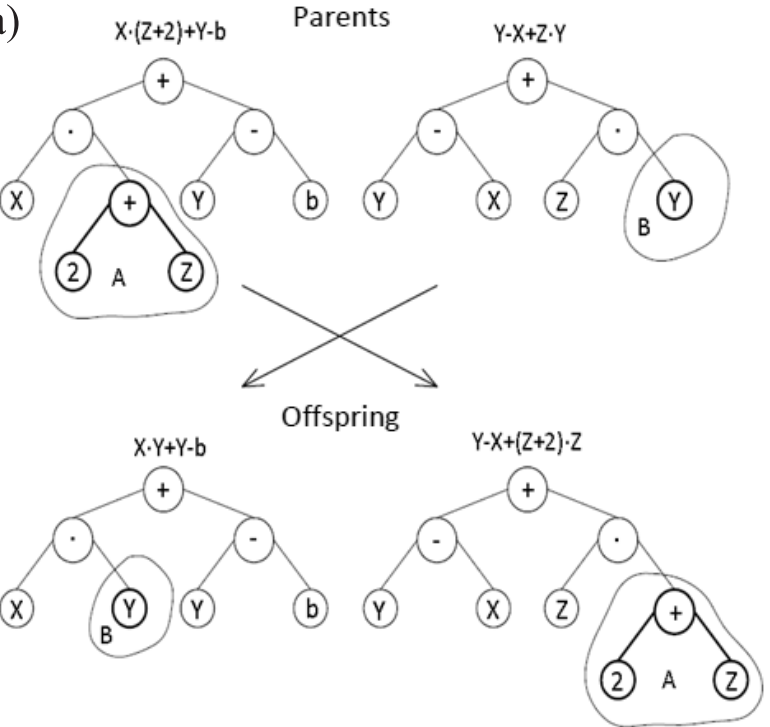

b)

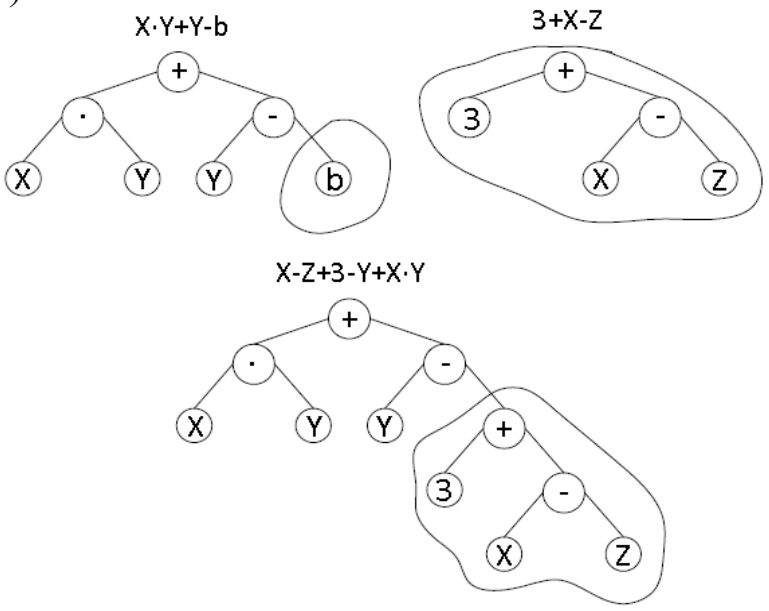

Fig. 1. Schematic activity of genetic operators for crossover a) and mutation $\mathrm{b}$ ).

initial number of individuals was assumed as $n=400$ and generations $\mathrm{N}=1000$, whereas the probability of mutation was assumed to be $\mathrm{P}_{\mathrm{m}}=0.25$ and that of crossover $\mathrm{P}_{\mathrm{c}}=0.65$.

\section{Results and Discussion}

The results of the conducted measurements (Table 1) show that the quality of wastewater reaching the treatment plant varied considerably in the analyzed period (2012 to 2015), which is confirmed by the variability of the measured concentrations: $\mathrm{BOD}=$ $127-557 \mathrm{mg} \mathrm{mgO} / \mathrm{dm}^{3}, \mathrm{COD}=384-1250 \mathrm{mgO} / \mathrm{dm}^{3}$, total suspended solids $\left(384-1250 \mathrm{mg} / \mathrm{dm}^{3}\right)$, permanganate index $\left(62-160 \mathrm{mg} / \mathrm{dm}^{3}\right)$, nitrogen compounds (eg. $\left.\mathrm{NO}_{3}{ }^{-}=0.05-1.10 \mathrm{mg} \mathrm{dm}{ }^{3}, \mathrm{~N}_{\text {total }}=39.91-124.09 \mathrm{mg} / \mathrm{dm}^{3}\right)$, total phosphorus (4.3-12.6 mg / $\left.\mathrm{dm}^{3}\right)$ and sulfates $\mathrm{SO}_{4}{ }^{2-}=$ $43-117 \mathrm{mg} / \mathrm{dm}^{3}$, and chloride $\left(\mathrm{Cl}^{-}=85.0-143.8 \mathrm{mg} / \mathrm{dm}^{3}\right)$. In the analyzed period the sludge temperature $\left(\mathrm{T}_{\text {sludge }}\right)$ varied from $11^{\circ} \mathrm{C}$ to $23^{\circ} \mathrm{C}$ and its concentration $\left(\mathrm{s}_{\text {sludge }}\right)$ in the bioreactor ranged from $1.19-5.9 \mathrm{~kg} / \mathrm{m}^{3}$. Moreover, the sludge recirculation degree $(\% \mathrm{rec})$ ranged from $44.59 \%$ to $167.55 \%$, whereas the recirculated sludge concentration $\left(\mathrm{s}_{\text {sl. rec. }}\right.$ ) varied from $4.800 \div 9.600 \mathrm{mg} / \mathrm{dm}^{3}$.

The maximum dosage amount of methanol $\left(\mathrm{m}_{\text {met }}\right)$ and PIX $\left(\mathrm{m}_{\mathrm{PIX}}\right)$ amounted to $4.56 \mathrm{~m}^{3}$ and $7.93 \mathrm{~m}^{3}$, respectively, and the amount of the sediment deposited in the primary clarifier $\left(\mathrm{m}_{\text {pr.cl }}\right)$ was equal to $54-317 \mathrm{~kg}$. Moreover, the oxygen concentration in the nitrification chamber $\left(\mathrm{s}_{\mathrm{O} 2,202,204,211}\right)$ varied from $0.61 \mathrm{mg} / \mathrm{dm}^{3}$ to $5.80 \mathrm{mg} / \mathrm{dm}^{3}$, whereas in the denitrification chamber $\left(\mathrm{s}_{\mathrm{O} 2,201,205}\right)$ it was equal to $0.00-0.04 \mathrm{mg} / \mathrm{dm}^{3}$.

Prior to statistical analyses, the collected measurement results were used to check the goodnessof-fit of the analyzed variables' distribution to normal distribution. Shapiro-Wilk test performed for this purpose confirmed that the analyzed variables have a distribution deviating from the normal, and therefore Spearman correlation coefficient was determined (Table 2).

Primarily, it should be noted that the settleability of the activated sludge depends on the season of the year. In winter $(r=0.58)$ and autumn $(r=0.34)$ the settleability rises, while during the summer $(r=-0.44)$ it is lower than in the spring $(\mathrm{r}=-0.21)$. This is also indicated by the values of the settleability medians for the winter, autumn, spring and summer seasons, which are $900 \mathrm{ml} / \mathrm{dm}^{3}, 830 \mathrm{ml} / \mathrm{dm}^{3}, 785 \mathrm{ml} / \mathrm{dm}^{3}$ and $705 \mathrm{ml} / \mathrm{dm}^{3}$, respectively. Based on the obtained results, it can be concluded that there is high correlation between the activated sludge settleability and the degree of recirculation $(\mathrm{r}=0.53)$, the concentration of sludge in biological reactor $(r=0.64)$ and sludge temperature $(\mathrm{r}=-0.58)$. In addition, there is an average correlation between the activated sludge settleability and the amount of wastewater flowing into the treatment plant $(r=-0.31)$, air temperature $(r=-0.37)$ and the temperature of the influent wastewater $(r=-0.45)$, the concentration of the recirculated sludge $(\mathrm{r}=0.40)$ and the oxygen concentration in the nitrification chamber $(r=-0.31)$. The above results are confirmed by analyses carried out by Lou and Zhao [9] as well as by Bagheri et al. [6], who have developed mathematical models using the method of artificial neural networks to forecast the sedimentation of activated sludge in municipal wastewater treatment plants using the results of measurements of the quantity and quality of wastewater and parameters of the biological reactor. The same relationships as in this paper have been obtained by Cortes et al. [4] who, using the classification trees method, developed a methodology to control sludge sedimentation, taking into account loads of incoming contaminants, parameters of the biological reactor and composition of the sludge bacterial flora of a sewage treatment plant located in the Catalonia area. The influence of temperature on the improvement of sedimentary abilities was also demonstrated by Rössle and Pretorius [5], who developed a non-linear regression 
Tab. 2. Pearson matrix of the correlation between the analyzed variables and the settleability of activated sludge.

\begin{tabular}{|c|c|c|c|c|c|c|c|c|}
\hline & \multicolumn{5}{|c|}{ Variable $\left(\mathrm{x}_{\mathrm{ij}}\right)$} & \multicolumn{4}{c|}{ Corr. coefficient $\left(\mathrm{x}_{\mathrm{ij}}-\mathrm{SE}\right)$} \\
\hline $\mathrm{j}=1$ & $\mathrm{i}=1$ & $\mathrm{i}=2$ & $\mathrm{i}=3$ & $\mathrm{i}=4$ & $\mathrm{i}=1$ & $\mathrm{i}=2$ & $\mathrm{i}=3$ & $\mathrm{i}=4$ \\
\hline $\mathrm{j}=2$ & winter & $\mathrm{R} . \mathrm{H}$. & $\mathrm{N}_{\text {total }}$ & $\mathrm{NO}_{3}^{-}$ & 0.58 & 0.42 & 0.33 & -0.20 \\
\hline $\mathrm{j}=3$ & spring & $\mathrm{BOD}$ & $\mathrm{N}_{\mathrm{Kjeh}}$ & $\mathrm{s}_{\mathrm{O} 2,201,205}$ & -0.21 & 0.39 & 0.33 & -0.31 \\
\hline $\mathrm{j}=4$ & summer & $\mathrm{COD}$ & $\mathrm{P}_{\text {total }}$ & $\mathrm{s}_{\mathrm{O} 2,211}$ & -0.44 & 0.23 & 0.19 & 0.31 \\
\hline $\mathrm{j}=5$ & $\mathrm{Q}_{\text {inf }}$ & $\mathrm{PI}$ & $\mathrm{SO}_{4}^{2-}$ & \%rec. & -0.31 & 0.19 & 0.12 & 0.53 \\
\hline $\mathrm{j}=6$ & $\mathrm{~T}_{\text {inf }}$ & $\mathrm{pH}$ & $\mathrm{T}_{\text {sludge }}$ & $\mathrm{m}_{\text {met }}$ & -0.45 & $-0.06^{*}$ & -0.58 & -0.20 \\
\hline $\mathrm{j}=7$ & $\mathrm{~T}_{\text {air }}$ & $\mathrm{NH}_{4}^{+}$ & $\mathrm{s}_{\text {sludge }}$ & $\mathrm{m}_{\mathrm{PIX}}$ & -0.37 & 0.33 & 0.64 & -0.22 \\
\hline $\mathrm{j}=8$ & $\mathrm{~W} . \mathrm{V}$. & $\mathrm{NO}_{2}{ }^{-}$ & $\mathrm{m}_{\text {pr.cl }}$ & $\mathrm{m}_{\mathrm{PAX}}$ & 0.11 & -0.13 & -0.28 & $0.02^{*}$ \\
\hline
\end{tabular}

* - variable at an adopted level of significance $\alpha=0.05$ is not statistically significant

relationship for the sedimentation forecast based on the results of temperature and sediment concentration measurements. The dependences obtained in the paper were also confirmed by the author's research [11], who using the logistic regression method demonstrated the influence of the increase of oxygen concentration in the nitrification chamber and of sediment temperature on improving the sedimentation abilities of the activated sludge.

Moreover, there is a weak correlation between the analyzed technological parameter of the sludge and the amount of the primary sludge $(r=-0.28)$ and the dosed methanol $(r=-0.20)$ acting as an additional source of carbon in the wastewater treatment process. Początek formularzaAnalyzing the obtained results (Table 1), it can be concluded that there is an average correlation between activated sludge settleability and BOD $(\mathrm{r}=0.39)$, as well as ammonia, Kjeldahl and total nitrogen $(r=0.33)$ concentrations. There is also a weak correlation between SE and COD $(r=0.23)$ and the concentrations of nitrate nitrogen $(\mathrm{r}=-0.28)$, nitrite nitrogen $(r=-0.20)$, total phosphorus $(r=0.19)$ and sulfates $(r=0.12)$.

The obtained $r$ values indicate that the relationships between the precipitation of the activated sludge and the above-mentioned wastewater quality indicators is non-linear. These relationships were found by Bagheri et al. [6] and by Szeląg and Gawdzik [10], who used artificial intelligence methods to estimate the sedimentation of activated sludge in municipal wastewater treatment plants. This approach, as well as confirmation of the results obtained in the paper, can be found in the works of Han and Qiao [7], Lou and Zhao [9] and Liu et al. [15].

The measurement results of the influent wastewater quantity and quality, the bioreactor's performance parameters and meteorological conditions provided the basis for the development of the regression models to predict activated sludge settleability. These analyzes focused on three options: the first took into account the physicochemical parameters of the influent wastewater and the abiotic factors (air and wastewater temperature, humidity, wind velocity, the value of BOD, COD, nitrogen compounds, total phosphorus, sulfates, chlorides, permanganate index); the next option took into consideration only the bioreactor parameters (sludge temperature, sludge concentration, recirculation degree, recirculated sludge concentration, oxygen concentration in the denitrification, nitrification and dephosphatation chambers); and the last option took into account the bioreactor parameters as well as the quality of the influent wastewater. On the basis of the conducted calculations, multiple regression equations were determined to predict the activated sludge settleability for:

- option I

$$
\begin{gathered}
S E=1.69 \cdot N_{\text {tot }}+ \\
-7.46 \cdot T_{\text {air }}+637.19 \\
\left(\mathrm{r}^{2}=0.42\right)
\end{gathered}
$$

- option II

$$
\begin{gathered}
S E=94.27 \cdot S_{\text {sludge }}-16.52 \cdot T_{\text {sludge }}- \\
-0.70 \cdot m_{\text {pr.cl }}+838.3 \\
\left(\mathrm{r}^{2}=0.52\right)
\end{gathered}
$$

- option III

$$
\begin{gathered}
S E=1.56 \cdot N_{\text {tot }}+0.07 \cdot B O D+9.44 \cdot P_{\text {tot }}- \\
-20.05 \cdot T_{\text {sludge }}+81.42 \cdot S_{\text {sludge }}+514.02 \\
\left(\mathrm{r}^{2}=0.63\right)
\end{gathered}
$$

Due to the stochastic character of the selection of the model variables in the genetic programming, certain regression relationships in different options (I-III) giving the best goodness of fit between the calculation results and the measurement data are presented below. 
On the basis of the performed analyses, the following empirical equations were given for:

-option I

$$
\begin{gathered}
S E=A \cdot T_{\text {air }}-B \cdot N_{\text {total }}+C\left(\mathrm{r}^{2}=0.56\right) \\
A=0.14 \cdot B O D-0.09 \cdot C O D-2.84 \cdot N_{\text {total }}+131
\end{gathered}
$$

$B=53.7-0.001 \cdot Q \quad-0.05 \cdot B O D-0.009 \cdot C O D$

$C=245.57-1.95 \cdot C O D+B O D \cdot(0.01 \cdot C O D-6.61)$

- option II

$$
\begin{gathered}
S E=A_{1} \cdot \% \text { rec }-B_{1} \cdot S_{\text {sludge }}+C_{1} \quad\left(\mathrm{r}^{2}=0.68\right) \\
A_{1}=1.08 \cdot T_{\text {sludge }}-16.05 \\
B_{1}=20.3 \cdot T_{\text {sludge }}+3.48 \cdot \% \text { rec }-0.23 \cdot T_{\text {sludge }} \cdot \% \text { rec } \\
C_{1}=2087-111.35 \cdot T_{\text {sludge }}
\end{gathered}
$$

- option III

$$
\begin{gathered}
S E=A_{2} \cdot S_{\text {sludge }}+B_{2} \cdot T_{\text {sludge }}-C_{2} \cdot N_{\text {total }}+D_{2} \\
\left(\mathrm{r}^{2}=0.73\right) \\
A_{2}=2.65 \cdot S_{\text {sludge }}+1.25 \cdot N_{\text {total }}-0.05 \cdot B O D-39.19 \\
B_{2}=13.2-0.01 \cdot B O D \\
C_{2}=0.89+0.01 \cdot B O D-0.08 \cdot T_{\text {sludge }}(7 \mathrm{c}) \\
D_{2}=787.5+1.71 \cdot B O D
\end{gathered}
$$

The calculations showed that the statistical models to predict the activated sludge settleability obtained by genetic programming are characterized by significantly better predictive ability than the models based on multiple linear regression.

\section{Conclusions}

The conducted analyses show that the activated sludge settleability is influenced by meteorological conditions (temperature and relative humidity of the air), physical parameters (temperature) and chemical factors (concentrations of nitrogen, total phosphorus, sulfates and BOD and COD) of the influent wastewater and the technological parameters of the bioreactor. Taking into account the predictive capacity of the obtained mathematical model, it can be concluded that it is not possible to determine activated sludge settleability by multiple regression due to the unsatisfactory value of the determination coefficient. The genetic programming method yielded significantly better prediction results of activated sludge settleability than the multiple regression method, as confirmed by the resultant values of the determination coefficients. The best sludge settleability results are obtained when the variables defining both the bioreactor performance parameters and the influent wastewater quality act as the independent variables for the model. The worst settleability values, on the other hand, were obtained when the variables depicting solely the quality of the wastewater flowing into the analyzed facility together with the meteorological conditions were used as the input data. Taking into account the resultant parameter values for the goodness of fit between the calculated and the measured settleability results in the obtained options, it can be concluded that only the model based on wastewater quality and the bioreactor performance parameters can be applied in practical analysis.

Considering the typically empirical character of the obtained mathematical models, it is advisable to perform further studies analyzing other facilities, with the objective of verifying the relationships presented in this paper for the prediction of the activated sludge settleability.

\section{Conflict of Interest}

All authors declare no conflict of interest.

\section{References}

1. ANDRZEJCZAK O., LIWARSKA-BIZUKOJĆ E. The effect of the pollutant load on the actived sludge flocks morphology. Gas Water and Sanitary Engineering, 12, 480, 2014 [In Polish].

2. TRACZEWSKA T. M. Biotic and abiotic factors in active sludge bulking. Ochrona Środowiska, 2, 29, 1997 [In Polish].

3. ZHANG CH.H., HU H.D., CHEN J., ZHANG W.W. GOU Y.J., NING K. Influential Factors on Activated Sludge Deterioration in Anoxic-Oxic (A/O) Biological Treatment Plant of Coking Wastewater. Pol. J. Environ. Stud., 22 (6) 1877, 2013

4. CORTÉS U., MARTINEZ M., COMAS J., SÁNCHEZMARRÉ M., RODRIDUEZ-RODA I.A. conceptual model to facilitate knowledge sharing for bulking solving in wastewater treatment plant. AI Communications, 16, 279, 2003.

5. RÖSSLE W.H., PRETORIUS W.A. Batch and automated SVI measurement based on the short - term temperature variations. Water SA, 34 (2), 237, 2008.

6. BAGHERI M., MIRBAGHERI S.A., BAGHERI Z., KAMARKHANI A.M. Modeling and optimization for 
a real wastewater treatment plant using hybrid artificial neural networks - genetic algorithm approach. Process Saf Environ. 95, 12, 2015.

7. HAN H., QIAO J. Hierarchical Neural Network Modeling Approach to Predict Sludge Volume Index of Wastewater Treatment Process. Control Systems Technology, IEEE Transactions on 21, 2423, 2013.

8. SHAHZAD M., KHAN J.S., PAUL P. Influence of the temperature on the performance of a full-scale activated sludge process operated at varying solids retention time whilst treating municipal sewage. Water, 7, 855, 2015.

9. LUO I., ZHAO Y. Sludge Bulking Prediction Using Principle Component Regression and Artificial Neural Network. Math. Prob. Eng. 2012, 1, 2012.

10. SZELĄG B., GAWDZIK J. Assessment of the Effect of Wastewater Quantity and Quality, and Sludge Parameters on Predictive Abilities of Non-Linear Models for Activated Sludge Settleability Predictions. Pol. J. Environ. Stud., 26 (1) $315,2016$.
11. SZELAG B., SIWICKI P. Application of the selected classification models to the analysis of the settling capacity of the activated sludge - case study. E3S Web of Conference, 17, 00089, 2017.

12. BEZAK-MAZUR E., STOIŃSKA R., SZELĄG B. Evaluation of the impact of operational parameters and particular filamentous bacteria on activated sludge volume index - case study. Annual Set The Environment Protection. 18, 487, 2016 [In Polish].

13. DHRYMES-PHOEBUS J. Mathematic for Econometrics, Springer, New York, 2013.

14. KOZA J.R. Genetic Programming: On the Programming of Computers by Natural Selection, MIT Press, Cambridge, 1992.

15. LIU Y., GUO J., WANG Q., HUANG D. Prediction of filamentous sludge bulking using a state - based Gaussian process regression model. Scientific Reports. 6, 31303, 2016. 